\title{
EFFICIENCY ESTIMATION OF SPECIALIZED MULTIFUNCTIONAL SHIPS AT OPTIMAL DESIGNING
}

\author{
Andrejs Zvaigzne ${ }^{1}$, Oleksandr Bondarenko ${ }^{2}$ \\ ${ }^{1}$ Latvian Maritime Academy \\ Riga, Latvia, 12-k Flotes Street, LV-1016 \\ Ph.:+37129478533, e-mail: andrejs.zvaigzne@latja.lv \\ ${ }^{2}$ Admiral Makarov National University of Shipbuilding \\ Mykolaiv, Ukraine, Geroev Ukraine Avenue 9, 54025 \\ Ph.:+380982441295,e-mail:oleksandr.bondarenko@nuos.edu.ua
}

\begin{abstract}
The effectiveness assessment of specialized ships was discussed. Three groups of criteria such as financially-economic, technical and operational were analyzed. As an integrated criterion, "cost-effectiveness" ratio was proposed to be used. Selection of the optimum design characteristics of specialized ships were offered to carried out by solving the optimization problem. The description of the optimization problem formulation and the method of its solution were presented.
\end{abstract}

Keywords: criteria, specialized ship, optimization, effectiveness

\section{Introduction}

Countries having access to the sea possess several privileges and rights, as well as responsibilities which are defined in international laws, treaties and conventions. These countries are obligated to guarantee safe sailing, search and rescue in case of an emergency, implementation of laws enforcement in their exclusive economic zone and territorial waters, their protection and defence, to provide hydrographic information as well as many other tasks. In order to fulfil these tasks, countries require specialized ships.

International requirements do not differentiate between large-scale and small-scale countries; these requirements are to be fulfilled regardless of the size of the coast, population or government budget.

Supply ships to support all the tasks a significant challenge for minor countries or countries with limited financial resources, as they are forced to fulfil these requirements with limited economic, financial and human capital.

In order to fulfil these requirements in Latvia, there are several organizations supervising implementation of legislation in the sea- the Coastguard of the Latvian Navy, the Latvian Border Guard, the Fishing Inspection, and the Hydrographic Service of the Sea Administration as well as others. Each of these organizations fulfils their own specific function (even though they tend to overlap quite often) and each requires its own specific type of sea ship, with its own specific constructional/technical and operational capabilities. For a country with highly limited resources, it will be rather challenging to meet these requirements. The problems with ship construction optimization were well covered by Deschamps and Trumbule (2004), Bertram et al. (2005), cost reduction during the construction phase was best explained by Caprace J.D., Rigo P., cost reduction during the ship lifecycle by US Defence Systems Management College Acquisition Logistics Guide 1997 and Brown and Salcedo (2003), Landamore et al., (2007).

Is it possible to optimize more the requirements for such a sea ship to reduce expenses? To answer this question, the author's objectives for this study is to analyse of the optimal criteria for the chosen sea vessel needed to fulfil as many requested tasks as possible- special multifunctional ship. The target of this research is to provide a solution and develop methodology of conceptual designing for a multifunctional platform in the early stages.

\section{The Defining of the Criteria}

The process of building a new sea ship requires thorough research and consideration; all factors, criteria and risks connected with the project need to be analysed before designing the ship. 
As with each project, the available knowledge is quite limited in the beginning, but it is also the time when the most important decisions are made. At the end of the project, the available knowledge is considerably higher, but not many major decisions are left to be made.

By understanding the required criteria for the new build ship, the amount of available knowledge at the beginning will increases, at the moment when it is most needed.

In this work, the following criteria will be examined: Economic criteria; Technical criteria; Operational criteria.

These factors, are certainly interconnected, but in order to better understand them, they will be examined individually.

\subsection{Economic criteria}

It is relatively easy to define Economic criteria (EC) for commercial ships, where the main criterion is the profit relating to their expenses. However, such a criterion is not possible for Navy, Coastguard or Border Guard ships and, therefore, the need for different criteria arises.

The most important EC is a political factor - how much does the government desire to fulfil the international requirements and how many resources is it ready to invest?

Another important issue of the EC is how rationally these resources are going to be spent? For this criterion, there is a need of not only the analysis of the construction expenses, but also the one of operational expenses.

EC and their associated expenses $\mathrm{S}_{\mathrm{i}}$ - cost of the ship lifecycle, can be divided into several categories:

$\mathrm{S}_{1}$. Research and Development (R\&D),

$\mathrm{S}_{2}$. Purchasing/ Construction,

$\mathrm{S}_{3}$. Operational expenses,

$\mathrm{S}_{4}$. Utilization. The total costs of the ship can be calculated as the sum of all of the aforementioned categories:

$S_{i}=S_{1}+S_{2}+S_{3}+S_{4}$

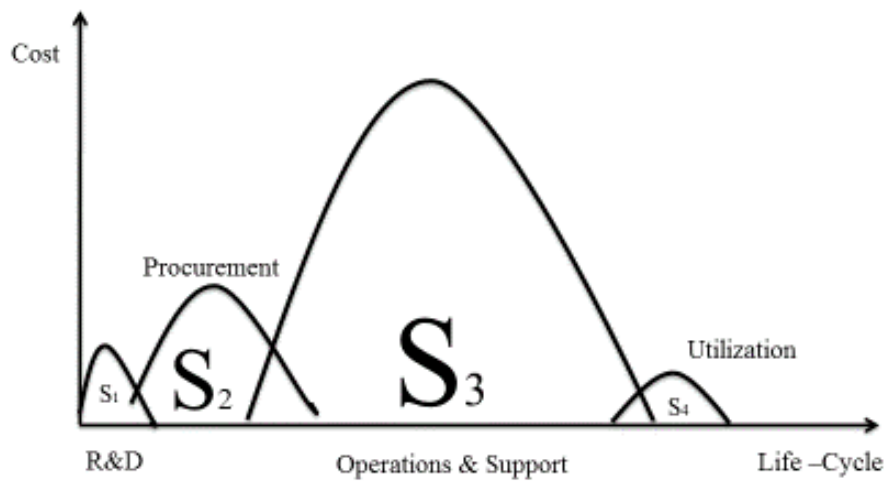

Figure 1. Expenses during the ship's life-cycle

By looking at each category individually, we will find that we are able to save money at almost all stages of ship life.

$R \& D$ is one of the most important phases and is also highly risky regarding completely new designs. In order to decrease the degree of risks and costs, it is possible to choose a pre-existing ship design. By choosing a pre-existing design, it is important to evaluate it according to its merits, its compliance with our requirements, as well as the costs of adjusting the ship for our requirements and the evaluation of whether our shipyards can build such a design.

Purchasing/Building. As we evaluate specialized multifunctional ships for our requirements, it is extremely desirable from both political and economic standpoints to build the ship in our own country's 
shipyards. From an operational viewpoint, building the ship in our local shipyards will allow shorter repair times, as well as guarantee their quality control and political independence from a faring government. More importantly, it can also provide us with a cheaper and quicker modernization, if the need arises.

Operational expenses. In general, operational expenses constitute $82 \%$ of the total ship costs. By taking into account the importance of this criterion, it is crucial to pay significant attention to it during the design phase. The best time to reduce operational costs is during the R\&D phase. Operational expenses can be divided into two broad categories: practical and administrative ones.

Practical operational expenses are expenses which are formed by the ship's staying at sea, the ship works, repair expenses, expenses on personnel and on modernization.

Administrative operational expenses are formed from ships administrative expenses, expenses from ensuring environmental protection and others.

The highly important factor in reducing operational expenses is ensuring better interdepartmental coordination. By correctly deciding on the technical specifications of newly built ships, as well as operational possibilities, use of modular equipment on the ship, how much the ship will be exploited and ensuring a strict interdepartmental contract, it is possible to substantially reduce future operational expenses. In Latvia, this point requires special attention.

Utilization. Same authors (Blanchard and Blyler, 2016) not include this type of expenses in total lifecycle cost, what is not correct. Ship utilization must to be included in to the common live cycle cost, which can be a significant part of expenses, especially in case when hard utilized materials were used in ships construction.

\subsection{Technical criteria}

Technical criteria consists of sailing capabilities, possibilities of placing various equipment, ship behaviour on waves, living conditions of the crew, manoeuvrability and ship speed.

\section{Sailing capabilities}

Sailing capabilities are the most important criterion for a ship. They are dependent on the ships requirements towards sailing region, main objectives of the ship, ship type, hull size, materials, engine power, equipment and other mechanisms.

\section{Possibilities of placing various equipment}

The capabilities of fulfilling objectives for each ship are determined by its equipment and hardware. Before designing a ship, it is imperative that the objectives of the ship are clearly understood. The average operational lifespan of a ship ranges from 23 to 35 years. This means that, when designing a ship, we must also consider the type of tasks the ship will fulfil in the future and what type of equipment it will require. Furthermore, taking into account the fact that the operational lifespan of equipment is much shorter than ships one, we must understand how important it is to ensure that equipment can be easily replaced. The best way to ensure such a fact is to place it in individual containers on the deck which will enable us to change the ship's configuration easily and quickly adapt the ship to new equipment and new tasks.

Such a tactic poses special requirements for the ship platform as it needs to have a large area of deck space and it has to be energy-efficient in order to sufficiently provide electricity to these modules.

\section{Ship behaviour on waves}

Ship's behaviour on waves is one of the most important criterions for ships which limits the ship's operational zone and limits its usage in poor weather conditions. Each ship owner wills to acquire a ship with perfect behaviour on waves, but that increases expenses.

Why is a stable ship so important? A ship is crewed by people and research has shown that, if vertical acceleration is greater than $2 \mathrm{~m} / \mathrm{s}^{2}$, then the crew does not feel comfortable. If vertical acceleration is greater than $4 \mathrm{~m} / \mathrm{s}^{2}$, then the crew becomes unable to fulfil their duties and the captain is forced to decrease either speed or change course or both. These factors are very important when the crew is required to make adequate and responsible decisions. It also affects the ability of specialized ships to fulfil their tasks. 
Ship stability affects the performance it sensors, for example, for towed sensors and towed cameras. With a stable ship it is much easier to perform search and rescue operations, lunching boats or divers, inspection of other ships at sea or to deliver personnel or cargo to other ships.

\section{Manoeuvrability}

Another very important criterion in the fulfilment of tasks for several specialized ships is manoeuvrability. For example, while conducting hydrographic measurements with a towed sonar, it is necessary that the ship strictly follows course at low speeds and that its performance is virtually unaffected by wind or currents. While conducting rescue or oil gathering operations it is important to be able to manoeuver with a minimal radius as well as to be able to retain position while sideways to waves and wind. In order to approach another ship's side in bad weather, good manoeuvrability is a must.

\section{Ship speed}

Several tasks for specialized ships require not only the ability to sail with maximum speed for a long period of time (interception, arresting, patrolling), but also the ability to sail with minimum speed for a long period of time (patrolling, sonar operations, fishing or ecological supervision, towing, oil combating). Special requirements are posed for the propellers of such ships, as they require minimal turbulence, for example, so as to not affect the performance of sonars. Such contradictory requirements pose a challenge to ship constructers as to how to combine them and what technology to use.

\section{Living conditions of the crew}

Specialised ships belong to the government and as such do not always have to conform to international standards and conventions. Nevertheless, the tendency for ship crews is to find employment with the best possible work conditions. Thus, while planning a new ship, it is important to ensure that it is as close as possible to international standards concerning the living conditions of the crew. That means that the ship is required to have more deck space.

By ensuring comfortable living conditions on the ship for the crew, the sailing safety of the ship is improved as well as the efficiency of the crew and the attractiveness of the profession (which is very important in the Latvian current demographic situation).

We can analyse what ship's technical criteria needed for different organizations: Coast guard, Navy, Border Guard, Fishing Inspection, and the Hydrographic Service.

\begin{tabular}{|l|c|c|c|c|c|}
\hline $\begin{array}{l}\text { Organization } \\
\text { Technical } \\
\text { criteria }\end{array}$ & Coastguard & Navy & $\begin{array}{l}\text { Hydrographic } \\
\text { Service }\end{array}$ & Border Guard & $\begin{array}{l}\text { Fishing } \\
\text { Inspection }\end{array}$ \\
\hline Sailing capabilities & 100 & 100 & 30 & 70 & 70 \\
\hline $\begin{array}{l}\text { Possibilities of } \\
\text { placing various } \\
\text { equipment }\end{array}$ & 70 & 100 & 100 & 30 & 30 \\
\hline $\begin{array}{l}\text { Ship behaviour on } \\
\text { waves }\end{array}$ & 100 & 100 & 30 & 70 & 50 \\
\hline $\begin{array}{l}\text { Manoeuvrability } \\
\text { Ship speed }\end{array}$ & 100 & 100 & 100 & 100 & 50 \\
\hline $\begin{array}{l}\text { Living conditions of } \\
\text { the crew }\end{array}$ & 70 & 100 & 50 & 100 & 50 \\
\hline
\end{tabular}

Figure 2. Ship's technical criteria for organizations 
Use of taxonomy scheme and according to authors expert estimate by given 100- for the most important, 70- important, 50- less important, 30- need to have for the applicable requirements, we can found area of the optimal "most important" technical criteria (blue) for the special multifunctional ship. Area of "important" (rose) requirements also need to be carefully considered.

\subsection{Operational criteria}

Let us list the possible missions specialized ships will have to do. Each mission consists of several elements (mission element):

Exclusive Economic zone (EEZ) control:

- Searching Suspected Illegal Activity Ship - (SIAV);

- Pursuit;

- Inspection, Boarding;

- Seize;

- Escorting;

- etc.

Search and Rescue (SAR) operations:

- SAR;

- Fire-fighting;

- Towing of a damage ship;

- Divers support.

Marine environmental protection (MEP):

- Localization of oil spill areas and liquidation of pollution;

- Fishing control;

- Inspection, Boarding;

- Environmental pollution control;

- Hydrographical surveillance and support.

Military readiness $(M R)$ :

- Interdiction;

- Delivery of an inspection group to the ship;

- Fulfilment of the ISPS code and its control;

- Gathering of oil or other hazardous materials;

- Towing of a damage ship;

- Divers support;

- Fire fighting;

- Ensuring of safe sailing (military functions);

- Anti-mine warfare;

- Anti-ship warfare;

- Anti-air warfare;

- Anti-submarine warfare;

- ABC defence;

- Mine deployment;

- Anti-saboteur warfare;

- Specialized transportation;

- Anti-blockade warfare;

- etc.

The functional opportunities expansion of the ship is possible with unmanned aerial vehicles (on small ships) or helicopters (on large ships).

Almost each and every one of these mission element requires specialized equipment and hardware. For example, the function of searching of SIAV is relatively similar to the function of searching an emergency object (object in distress) and may be performed using the same equipment. However, some of these tasks can be combined or fulfilled by one platform with changing its equipment.

We can do similar taxonomy scheme for the operational criteria, and define area of the most common required operational criteria for the new special multifunctional ship (Blue and rose zone). 


\begin{tabular}{|c|c|c|c|c|c|}
\hline $\mathrm{P}_{\text {Operational criteria }}^{\text {Organization }}$ & Coastguard & Navy, & $\begin{array}{l}\text { Border } \\
\text { Guard, }\end{array}$ & $\begin{array}{l}\text { Fishing } \\
\text { Inspection, }\end{array}$ & $\begin{array}{l}\text { Hydrographic } \\
\text { Service }\end{array}$ \\
\hline SIAV & 100 & 100 & 100 & 70 & 0 \\
\hline Pursuit & 100 & 100 & 100 & 100 & 0 \\
\hline Inspection, Boarding & 100 & 100 & 100 & 100 & 0 \\
\hline Seize & 50 & 100 & 50 & 30 & 0 \\
\hline Escorting & 70 & 100 & 50 & 30 & 0 \\
\hline$S A R$ & 100 & 70 & 70 & 30 & 30 \\
\hline Fire-fighting & 100 & 30 & 30 & 0 & 0 \\
\hline Towing of a damage ship & 100 & 30 & 30 & 0 & 0 \\
\hline Divers support & 70 & 100 & 30 & 0 & 50 \\
\hline $\begin{array}{l}\text { Localization of oil spill areas and } \\
\text { liquidation of pollution }\end{array}$ & 100 & 0 & 0 & 0 & 0 \\
\hline Fishing control & 30 & 0 & 0 & 100 & 0 \\
\hline Environmental pollution control & 100 & 30 & 70 & 70 & 0 \\
\hline Hydrographical surveillance and support & 30 & 30 & 0 & 0 & 100 \\
\hline Interdiction & 70 & 100 & 50 & 0 & 0 \\
\hline Fulfilment of the ISPS code and its control & 100 & 100 & 100 & 0 & 0 \\
\hline Ensuring of safe sailing & 100 & 100 & 0 & 0 & 100 \\
\hline Anti-mine warfare & 30 & 100 & 0 & 0 & 0 \\
\hline Anti-ship warfare & 30 & 100 & 0 & 0 & 0 \\
\hline Anti-air warfare & 0 & 100 & 0 & 0 & 0 \\
\hline Anti-submarine warfare & 0 & 100 & 0 & 0 & 0 \\
\hline Anti-blockade warfare & 30 & 100 & 30 & 0 & 0 \\
\hline Anti-saboteur warfare & 70 & 100 & 70 & 0 & 0 \\
\hline Specialized transportation & 70 & 100 & 50 & 0 & 0 \\
\hline$A B C$ defence & 0 & 100 & 0 & 0 & 0 \\
\hline Mine deployment & 30 & 100 & 0 & 0 & 0 \\
\hline
\end{tabular}

Figure 3. Ship's operational criteria for organizations

The analysis of common and each operative criteria has to be made thoroughly, taking into account both the technical requirements and EC.

\section{Efficiency Estimation of Specialized Multifunctional Ships}

Functional abilities of ship platform are directly related to its displacement and dimensions. The extension of functional abilities leads to increasing displacement of the platform-ship, and accordingly the value of its life cycle. Hence, in order to solve a difficult task of finding a compromise between the limited financial resources and the expansion of the functionality of the platform, it is necessary to use an optimized approach. Application of this approach involves development of a mathematical model of the platform and an operation model.

With the help of the mathematical model, platform dimensions, displacement, seaworthiness abilities, technical and partially financial and economic criteria such as cost of design, construction and recycling are defined. The mathematical model of the platform is developed according to its architectural and construction type (e.g. a monohull ship, a catamaran, a Small Waterplane Area Twin Hull ship, a fast interceptor boats, etc.

The operation model is used to determine values of performance criteria. In this paper, the values of performance criteria are calculated by simulation platform basic missions. For each mission, a platform action scenario is designed and effectiveness of the mission implementation is determined. For example, the probability $E$ of successful implementation of detection and seize operations of the SIAV is calculated as follows:

$E=P_{1} P_{2}$, 
where $P_{1}$ - probability of SIAV detection by using available means on the platform; $P_{2}$ - probability of SIAV seize, which is determined by technical characteristics of the platform: seaworthiness, speed and weapons presence.

The problem of optimal design is formulated as follows:

Find

$F(X, C) \rightarrow \min (\max )$

subject to

$D=\left\{X \in R^{n} \mid g_{j}(X, C) \geq 0, \quad j \in[1, p], g_{l}(X, C)=0, \quad l \in[p+1, k]\right\}$

$X \in D \subset R^{n}$

where $F(X, C)$ is an objective function; $\min (\max )$ is a minimum or maximum objective function; $X\left(x_{1}, \ldots, x_{n}\right)$ is vector of the desired characteristics of the platform (the vector of independent variables); $n$ is a number of independent variables; $C\left(\mathrm{C}_{1}, \ldots, C_{m}\right)$ is a vector of the parameters forming the design task; $m$ is a number of the $C$ vector parameters; $D$ is a feasible set of the search; $R^{n}$ is $n$-dimensional Euclidean space; $g_{j}(X, C)$ are constraints in form of equations; $j$ is index for constrains in the form of equations; $l$ is index for constrains in the form of inequalities; $p$ is a number of optimization problem constrains in the form of inequalities; $k$ is a total number of optimization problem constraints.

As the objective function of the optimization problem $F(X, C)$, the ratio of "cost-effectiveness" is used

$$
F(X, C)=\frac{S_{i}}{E} \rightarrow \min
$$

In this article, the cost of platform lifecycle $\mathrm{S}_{\mathrm{i}}$ is used as the value index. This indicator is a random variable. It has its probability distributions and is determined in formula (1), where $S_{1}, S_{2}, S_{3}$, $S_{4}$ are design, construction, operation and utilization platform costs, set in connection with variations in probability distributions of current prices. To determine probability characteristics of the costs indicator $\mathrm{S}_{\mathrm{i}}$, the method of statistical tests (Monte Carlo method) is used (Chan, 2013).

The vector $C$ consists of the main characteristics of the design task platform such as power plant type, detection tools type, the weapons types, navigation area and size of the patrol area, maximum speed $V_{S}$, patrol speed, endurance, miles; hull and superstructure material; maximal seaworthiness. In addition, it is assumed that the customer may specify extra requirements for the desired characteristics of the platform.

The composition of the initial data also includes the data, set by the designer, which determine some technical solutions, as well as further information on the technical and economic standards.

The vector composition of independent variables of the optimization problem of designing a multifunctional platform depends on the chosen architectural and construction type of the platform. For example, for a monohull ship the independent variables are (vector $X$ ): Length-to-Beam ratio $X_{1}=L / B$, beam-to-draft ratio $X_{2}=B / T$, depth-to-draft ratio $X_{3}=H / T$, block coefficient $X_{4}=C_{b}$, displacement $X_{5}=\Delta$.

For the platform of Small Waterplane Area Twin Hull ship, the vector of independent variables includes the following features: $x_{1}-$ relative length of lower hull $l_{H} ; x_{2}$ - slenderness coefficient of strut $l_{S} ; x_{3}$ - waterplane area strut coefficient $C_{W P S} ; x_{4}$ - relative waterplane area $k_{W} ; x_{5}$ - ratio of the distance between lower hull center-line to the length of the ship; $x_{6}$ - ratio of the ship draft to the lower hull diameter $l_{d} ; x_{7}$ - ratio of the lower hull beam to its depth $b_{H} ; x_{8}$ - lower hull prismatic coefficient $C_{p} ; x_{9}$ - factor of the lower hull nose shape $n_{f} ; x_{10}$ - factor of the lower hull tail shape $n_{a} ; x_{11}$ - factor of the lower hull cross section shape $n_{h} ; x_{12}$ - strut nose and tail shape factor $n_{s} ; x_{13}$ - hull nose length to lower hull ratio $l_{N H} ; x_{14}$ - strut nose length to strut length ratio $l_{N S} ; x_{15}$ - payload coefficient $\eta_{\mathrm{P}} ; x_{16}-$ strut setback $s \_b$. 
The feasible set of the search $D$ is formed on the basis of two different groups of constraints such as direct and functional, which are in a form of inequalities or equalities and set in (3) using the function $g(X, C)$. Direct constraints set upper and lower allowable values of the independent variables:

$x_{i}^{\min } \leq x_{i} \leq x_{i}^{\max }, i=1, \ldots, n$.

where $x_{i}^{\min }$ is lower bounds on the independent variable, $x_{i}^{\max }$ is upper bounds on the independent variable; $x_{i}$ is values of the independent variables; $n$ is number of independent variables; $i$ is index for independent variables.

Functional constraints include requirements for platform qualities:

$A_{j}(x) \leq a_{j}$,

where $A_{j}(X)$ and $a_{j}$ are the calculated value and the required value of the vessel characteristics correspondingly.

All constraints must be presented in a form of one-sided inequalities.

$G_{j}(x, U) \geq 0$.

For $A_{j}(x) \leq a_{j}$

$G_{j}(x, U)=\frac{a_{j}}{A_{j}(x)}-1 \geq 0$.

For $A_{j}(x)>a_{j}$

$G_{j}(x, U)=\frac{A_{j}(x)}{a_{j}}-1 \geq 0$,

where $G_{j}$ is the vector constraint.

In the optimization task, the functional constraints, which determine requirements for platform seaworthiness, navigation safety, financial resources, etc., are usually used. These constraints are formed in compliance with regulations requirements of various international maritime organizations.

One of the task features is that the criteria $F(X, C) \rightarrow$ min is the complex function of many random variables. For example, ship speed depends on the characteristics of the random combination of wind and waves during the voyage. In the case, when the factors determining the properties of the system are random variables or system estimation depends on random environment functioning, randomized criteria are used. This criterion itself can be seen as the probability of the ship realization of its properties under certain conditions. In addition, the task due to the nonlinearity of dependencies within the constraints and the objective function, is related to the problems of nonlinear programming with constraints.

As the considered optimization task is a non-linear task with constraints, the genetic algorithm or one of the constrained optimization techniques can be applied to solve it (Rutkovskaya et al., 2006).

\section{Conclusions}

Choosing criteria for a specialized ship is a difficult process which requires deep knowledge in multiple disciplines. The working group for selecting a ship has to consist of experts of different fields, who can freely analyse and compare several possible solutions. Using the aforementioned criteria, it is possible to model different ship configurations, research how technical requirements collaborate with operational requirements and their effects on financially-economic indicators, as a result of which it becomes possible to choose the most adequate and effective project.

In order to solve the problem of the optimum characteristics selection of the multifunctional platform using these criteria, the optimization approach has been proposed. The task formulation description and the method of its solution have been presented. The developed methodology of designing a multifunctional platform can be used in the early stages of a conceptual design. 


\section{References}

1. Back, T. (1996) Evolutionary Algorithms in Theory and Practice. New York: Oxford University Press.

2. Bertram, V., Maisonneuve, J., Caprace, J., Rigo, P. (2005) Cost Assessment in Ship Production. RINA.

3. Blanchard, S.B., Blyler, J.E., (2016) Systems Engineering Management, fifth edition. Wiley.

4. Bondarenko, O.V. (2013) Determination of the main characteristics of the small waterplane area twin hull ships at the initial stage of design, Polish Maritime Research, Vol. 20, Issue 1(77), pp.11-22.

5. Brown, A., Salcedo, J., (2003) Multiple-Objective Optimization in Naval Ship Design, Naval Engineers Journal, Volume 115, Number 4, 1 October, pp. 49-62(14) American Society of Naval Engineers

6. Caprace, J.D., Rigo, P. Multi-Criteria Decision Support for Cost Assessment Techniques in Shipbuilding Industry, viewed 15.01.2017 https://orbi.ulg.ac.be/bitstream/2268/9967/1/03_Caprace.pdf

7. Chan, V. (2013) Theory and Applications of Monte Carlo Simulations. InTech.

8. Davis, L. (1991) Handbook of Genetic Algorithms. New York: Van Nostrand.

9. Deschamps, L., Trumbule, J. (2004) Chapter 10 - Cost Estimation, Ship Design and Construction. SNAME.

10. Landamore, M., Birmingham, R., Downie, M., (2007) Establishing the Economic and Environmental Life Cycle Costs of Marine Systems: a Case Study from the Recreational Craft Sector. Marine Technology, 2(44):106-117, April 2007.

11. Law, A.M. (2015) Simulation Modeling and Analysis. New York: McGraw-Hill Publ.

12. Michalewicz, Z. (1996) Genetic Algorithms + Data Structures = Evolution Programs. BerlinHeidelberg: Springer-Verlag.

13. Rutkovskaya, D., Pilinskiy, M., Rytkovskiy, L.(2006) Neural Networks, Genetic Algorithms and Fuzzy Systems. Moscow: Goryachaya liniya - Telekom Publ,

14. Sivanandam, S.N., Deepa, S.N. (2007) Introduction to Genetic Algorithms. New York: Springer Publ.

15. Sovetov, B.YA., Yakovlev, S.A. (2009) Simulation of Systems. Moscow: Vysshaya shkola Publ.

16. US Defense Systems Management College (1997, third edition), Acquisition Logistics Guide. FORT BELVOIR, VA 22060-5565 U.S. Government Printing Office Superintendent of Documents, Mail Stop: SSOP, Washington, DC 20402-9328 